\title{
Permanence and global attractivity of a nonautonomous modified Leslie-Gower predator-prey model with Holling-type II schemes and a prey refuge
}

Xiangdong $\mathrm{Xie}^{1^{*}}$, Yalong Xue ${ }^{1}$, Jinhuang Chen ${ }^{2}$ and Tingting $\mathrm{Li}^{3}$

"Correspondence: latexfzu@126.com

1 Department of Mathematics, Ningde Normal University, Ningde, Fujian 352300, P.R. China

Full list of author information is available at the end of the article

\begin{abstract}
A nonautonomous modified Leslie-Gower predator-prey model with Holling-type II schemes and a prey refuge is studied in this paper. Persistent property and stability property of the system are investigated. Some findings about the influence of prey refuge are obtained.
\end{abstract}

MSC: 34D23; 92D25; 34D20; 34D40

Keywords: predator; prey; permanence; global stability

\section{Introduction}

Throughout this paper, for a bounded continuous function $g$ defined on $R$, let $g^{L}$ and $g^{M}$ be defined as

$$
g^{L}=\inf _{t \in R} g(t), \quad g^{M}=\sup _{t \in R} g(t)
$$

During the last two decades, the study of dynamic behaviors of predator-prey system incorporating a prey refuge become one of the most important research topic, see [1-45] and the references cited therein. In [1], Yue proposed and studied the following modified Leslie-Gower predator-prey model with Holling-type II schemes and a prey refuge:

$$
\begin{aligned}
& \dot{x}(t)=x\left(r_{1}-b_{1} x-\frac{a_{1}(1-m) y}{(1-m) x+k_{1}}\right), \\
& \dot{y}(t)=y\left(r_{2}-\frac{a_{2} y}{(1-m) x+k_{2}}\right),
\end{aligned}
$$

where $x(t)$ and $y(t)$ denote the densities of the predator and prey species at time $t$, respectively, and all the coefficients are all positive constants, $0 \leq m<1$. Such a topic as the global stability property of the positive equilibrium was investigated.

Many authors $[2,4,5,8,9]$ argued that with the biological and environmental change of the circumstance, it is reasonable to propose and study the nonautonomous system, the

(c) 2016 Xie et al. This article is distributed under the terms of the Creative Commons Attribution 4.0 International License (http://creativecommons.org/licenses/by/4.0/), which permits unrestricted use, distribution, and reproduction in any medium, provided you give appropriate credit to the original author(s) and the source, provide a link to the Creative Commons license, and indicate if changes were made. 
success of $[2,4,5,8,9]$ motivates us to propose the corresponding nonautonomous case of system (1.1), i.e., the following system:

$$
\begin{aligned}
& \dot{x}(t)=x\left(r_{1}(t)-b_{1}(t) x-\frac{a_{1}(t)(1-m(t)) y}{(1-m(t)) x+k_{1}(t)}\right), \\
& \dot{y}(t)=y\left(r_{2}(t)-\frac{a_{2}(t) y}{(1-m(t)) x+k_{2}(t)}\right),
\end{aligned}
$$

where $x(t)$ and $y(t)$ denote the densities of the predator and prey species at time $t$, respectively; One could refer to [1] for the biological meaning of the coefficients. Throughout this paper, we assume that

$\left(H_{1}\right) r_{i}(t), k_{i}(t), a_{i}(t), i=1,2, m(t), b_{1}(t)$ are continuous and strictly positive functions, which satisfy

$$
\begin{aligned}
& \min \left\{r_{i}^{L}, k_{i}^{L}, a_{i}^{L}, m^{L}, b_{1}^{L}\right\}>0, \\
& \max \left\{r_{i}^{M}, k_{i}^{M}, a_{i}^{M}, m^{M}, b_{1}^{M}\right\}<+\infty .
\end{aligned}
$$

We consider (1.2) together with the following initial conditions:

$$
x(0)>0, \quad y(0)>0 .
$$

It is not difficult to see that solutions of (1.2)-(1.3) are well defined for all $t \geq 0$ and satisfy

$$
x(t)>0, \quad y(t)>0 \quad \text { for all } t \geq 0 .
$$

The paper is arranged as follows: In Section 2, we obtain sufficient conditions which guarantee the permanence of the system (1.2). In Section 3, we obtain sufficient conditions which ensure the global attractivity of the system (1.2). In Section 4, an example together with its numeric simulations illustrates the feasibility of the main results. We end this paper by a brief discussion.

\section{Permanence}

Lemma 2.1 Let $(x(t), y(t))^{T}$ be any solution of system (1.2) with the initial conditions (1.3), then

$$
\begin{aligned}
& \limsup _{t \rightarrow+\infty} x(t) \leq \frac{r_{1}^{M}}{b_{1}^{L}} \stackrel{\text { def }}{=} M_{1}, \\
& \limsup _{t \rightarrow+\infty} y(t) \leq \frac{r_{2}^{M}\left(\left(1-m^{L}\right) M_{1}+k_{2}^{M}\right)}{a_{2}^{L}} \stackrel{\text { def }}{=} M_{2} .
\end{aligned}
$$

Proof Let $(x(t), y(t))^{T}$ be any solution of system (1.2) with the initial conditions (1.3). From the first equation of system (1.2), it follows that

$$
\begin{aligned}
\dot{x}(t) & =x\left(r_{1}(t)-b_{1}(t) x-\frac{a_{1}(t)(1-m(t)) y}{(1-m(t)) x+k_{1}(t)}\right) \\
& \leq x\left(r_{1}^{M}-b_{1}^{L} x\right) .
\end{aligned}
$$


Applying Lemma 2.3 in [46] to (2.2), it immediately follows that

$$
\limsup _{t \rightarrow+\infty} x(t) \leq \frac{r_{1}^{M}}{b_{1}^{L}} \stackrel{\text { def }}{=} M_{1} .
$$

For any positive constant $\varepsilon>0$ small enough, it follows from (2.3) that there exists a $T_{1}>0$ such that

$$
x(t)<M_{1}+\varepsilon \quad \text { for all } t \geq T_{1} .
$$

For $t>T_{1},(2.4)$ together with the second equation of system (1.2) leads to

$$
\begin{aligned}
\dot{y}(t) & =y\left(r_{2}(t)-\frac{a_{2}(t) y}{(1-m(t)) x+k_{2}(t)}\right) \\
& \leq y\left(r_{2}^{M}-\frac{a_{2}^{L}}{\left(1-m^{L}\right)\left(M_{1}+\varepsilon\right)+k_{2}^{M}} y\right) .
\end{aligned}
$$

Applying Lemma 2.3 in [46] to (2.5), it immediately follows that

$$
\limsup _{t \rightarrow+\infty} y(t) \leq \frac{r_{2}^{M}\left(\left(1-m^{L}\right)\left(M_{1}+\varepsilon\right)+k_{2}^{M}\right)}{a_{2}^{L}} .
$$

Setting $\varepsilon \rightarrow 0$, then

$$
\limsup _{t \rightarrow+\infty} y(t) \leq \frac{r_{2}^{M}\left(\left(1-m^{L}\right) M_{1}+k_{2}^{M}\right)}{a_{2}^{L}} \stackrel{\text { def }}{=} M_{2} .
$$

Lemma 2.2 Let $(x(t), y(t))^{T}$ be any solution of system (1.2) with the initial conditions (1.3), assume that

$$
r_{1}^{L}>\frac{a_{1}^{M}\left(1-m^{L}\right) M_{2}}{k_{1}^{L}}
$$

holds, then

$$
\begin{aligned}
& \liminf _{t \rightarrow+\infty} x(t) \geq \frac{r_{1}^{L} k_{1}^{L}-a_{1}^{M}\left(1-m^{L}\right) M_{2}}{k_{1}^{L} b_{1}^{M}} \stackrel{\text { def }}{=} m_{1}, \\
& \liminf _{t \rightarrow+\infty} y(t) \geq \frac{r_{2}^{L}\left(\left(1-m^{M}\right) m_{1}+k_{2}^{L}\right)}{a_{2}^{M}} \stackrel{\text { def }}{=} m_{2} .
\end{aligned}
$$

Proof Condition (2.8) implies that one could choose $\varepsilon>0$ small enough such that

$$
r_{1}^{L}>\frac{a_{1}^{M}\left(1-m^{L}\right)\left(M_{2}+\varepsilon\right)}{k_{1}^{L}}
$$

holds. For this $\varepsilon$, it follows from (2.7) that there exists a $T_{2}>T_{1}$ such that

$$
y(t)<M_{2}+\varepsilon \quad \text { for all } t \geq T_{2}
$$


Let $(x(t), y(t))^{T}$ be any solution of system (1.2) with the initial conditions (1.3). For $t>T_{2}$, (2.12) together with the first equation of system (1.2) leads to

$$
\begin{aligned}
\dot{x}(t) & =x\left(r_{1}(t)-b_{1}(t) x-\frac{a_{1}(t)(1-m(t)) y}{(1-m(t)) x+k_{1}(t)}\right) \\
& \geq x\left(r_{1}^{L}-\frac{a_{1}^{M}\left(1-m^{L}\right)\left(M_{2}-\varepsilon\right)}{k_{1}^{L}}-b_{1}^{M} x\right) .
\end{aligned}
$$

Applying Lemma 2.3 in [46] to (2.13), it immediately follows that

$$
\liminf _{t \rightarrow+\infty} x(t) \geq \frac{r_{1}^{L}-\frac{a_{1}^{M}\left(1-m^{L}\right)\left(M_{2}-\varepsilon\right)}{k_{1}^{L}}}{b_{1}^{M}} .
$$

Setting $\varepsilon \rightarrow 0$, then

$$
\liminf _{t \rightarrow+\infty} x(t) \geq \frac{r_{1}^{L} k_{1}^{L}-a_{1}^{M}\left(1-m^{L}\right) M_{2}}{k_{1}^{L} b_{1}^{M}} \stackrel{\text { def }}{=} m_{1}
$$

Let $\varepsilon>0$ be any positive constant small enough such that $\varepsilon<\frac{1}{2} m_{1}$. It then follows from (2.15) that there exists a $T_{3}>T_{2}$, such that

$$
x(t)>m_{1}-\varepsilon \quad \text { for all } t \geq T_{3} .
$$

From the second equation of system (1.2), it follows that

$$
\begin{aligned}
\dot{y}(t) & =y\left(r_{2}(t)-\frac{a_{2}(t) y}{(1-m(t)) x+k_{2}(t)}\right) \\
& \geq y(t)\left[r_{2}^{L}-\frac{a_{2}^{M} y(t)}{\left(1-m^{M}\right)\left(m_{1}-\varepsilon\right)+k_{2}^{L}}\right] .
\end{aligned}
$$

Applying Lemma 2.3 in [46] to (2.17), it immediately follows that

$$
\liminf _{t \rightarrow+\infty} y(t) \geq \frac{r_{2}^{L}\left(\left(1-m^{M}\right)\left(m_{1}-\varepsilon\right)+k_{2}^{L}\right)}{a_{2}^{M}}
$$

Setting $\varepsilon \rightarrow 0$, then

$$
\liminf _{t \rightarrow+\infty} y(t) \geq \frac{r_{2}^{L}\left(\left(1-m^{M}\right) m_{1}+k_{2}^{L}\right)}{a_{2}^{M}} \stackrel{\text { def }}{=} m_{2} .
$$

As a direct corollary of Lemma 2.1 and 2.2, we have the following.

Theorem 2.1 Assume that (2.8) holds, then system (1.2)-(1.3) is permanent. 


\section{Global attractivity}

Before we state the main result of this section, we introduce some notations. Set

$$
\begin{aligned}
& \Delta_{1}\left(m_{1}\right) \stackrel{\text { def }}{=}\left((1-m(t)) m_{1}+k_{1}(t)\right)^{2}, \\
& \Delta_{2}\left(m_{1}\right) \stackrel{\text { def }}{=}\left((1-m(t)) m_{1}+k_{2}(t)\right)^{2}, \\
& \Delta_{2}\left(M_{1}\right) \stackrel{\text { def }}{=}\left((1-m(t)) M_{1}+k_{2}(t)\right)^{2},
\end{aligned}
$$

and

$$
\begin{aligned}
& \Gamma_{1}(t) \stackrel{\text { def }}{=} b_{1}(t)-\frac{a_{1}(t)(1-m(t))^{2} M_{2}}{\Delta_{1}\left(m_{1}\right)}-\frac{a_{2}(t)(1-m(t)) M_{2}}{\Delta_{2}\left(m_{1}\right)}, \\
& \Gamma_{2}(t) \stackrel{\text { def }}{=} \frac{a_{2}(t) k_{2}(t)}{\Delta_{2}\left(M_{1}\right)}+\frac{a_{2}(t)(1-m(t)) m_{1}}{\Delta_{2}\left(M_{1}\right)} \\
& \quad-\frac{a_{1}(t)(1-m(t)) k_{1}(t)}{\Delta_{1}\left(m_{1}\right)}-\frac{a_{1}(t)(1-m(t))^{2} M_{1}}{\Delta_{1}\left(m_{1}\right)} .
\end{aligned}
$$

Theorem 3.1 Assume that all the conditions of Theorem 2.1 hold, assume further that

$$
\liminf _{t \rightarrow+\infty}\left\{\Gamma_{1}(t), \Gamma_{2}(t)\right\}>0
$$

then for any positive solutions $(x(t), y(t))^{T}$ and $\left(x_{1}(t), y_{1}(t)\right)^{T}$ of system (1.2), one has

$$
\lim _{t \rightarrow+\infty}\left(\left|x(t)-x_{1}(t)\right|+\left|y(t)-y_{1}(t)\right|\right)=0 .
$$

Proof Condition (3.3) implies that there exists a small enough positive constant $\varepsilon$ (without loss of generality, we may assume that $\left.\varepsilon<\frac{1}{2}\left\{m_{1}, m_{2}\right\}\right)$ such that

$$
\begin{aligned}
\Gamma_{1}(\varepsilon, t)= & b_{1}(t)-\frac{a_{1}(t)(1-m(t))^{2}\left(M_{2}+\varepsilon\right)}{\Delta_{1}\left(m_{1}^{\varepsilon}\right)} \\
& -\frac{a_{2}(t)(1-m(t))\left(M_{2}+\varepsilon\right)}{\Delta_{2}\left(m_{1}^{\varepsilon}\right)} \geq \varepsilon, \\
\Gamma_{2}(\varepsilon, t)= & \frac{a_{2}(t) k_{2}(t)}{\Delta_{2}\left(M_{1}^{\varepsilon}\right)}+\frac{a_{2}(t)(1-m(t))\left(m_{1}-\varepsilon\right)}{\Delta_{2}\left(M_{1}^{\varepsilon}\right)} \\
& -\frac{a_{1}(t)(1-m(t)) k_{1}(t)}{\Delta_{1}\left(m_{1}^{\varepsilon}\right)}-\frac{a_{1}(t)(1-m(t))^{2}\left(M_{1}+\varepsilon\right)}{\Delta_{1}\left(m_{1}^{\varepsilon}\right)} \geq \varepsilon,
\end{aligned}
$$

where

$$
\begin{aligned}
& \Delta_{1}\left(m_{1}^{\varepsilon}\right)=\left((1-m(t))\left(m_{1}-\varepsilon\right)+k_{1}(t)\right)^{2}, \\
& \Delta_{2}\left(m_{1}^{\varepsilon}\right)=\left((1-m(t))\left(m_{1}-\varepsilon\right)+k_{2}(t)\right)^{2}, \\
& \Delta_{2}\left(M_{1}^{\varepsilon}\right)=\left((1-m(t))\left(M_{1}+\varepsilon\right)+k_{2}(t)\right)^{2} .
\end{aligned}
$$

For two arbitrary positive solutions $(x(t), y(t))^{T}$ and $\left(x_{1}(t), y_{1}(t)\right)^{T}$ of system (1.2), for the above $\varepsilon>0$, it then follows from (2.1), (2.15), and (2.19) that there exists a $T>T_{3}$, such 
that for all $t \geq T$,

$$
\begin{array}{ll}
x(t), x_{1}(t)<M_{1}+\varepsilon, & y(t), y_{1}(t)<M_{2}+\varepsilon, \\
x(t), x_{1}(t)>m_{1}-\varepsilon, & y(t), y_{1}(t)>m_{2}-\varepsilon .
\end{array}
$$

Set

$$
\begin{aligned}
& \Delta_{1}\left(x(t), x_{1}(t)\right)=\left((1-m(t)) x_{1}(t)+k_{1}(t)\right)\left((1-m(t)) x(t)+k_{1}(t)\right), \\
& \Delta_{2}\left(x(t), x_{1}(t)\right)=\left((1-m(t)) x_{1}(t)+k_{2}(t)\right)\left((1-m(t)) x(t)+k_{2}(t)\right) .
\end{aligned}
$$

Now we let

$$
\begin{aligned}
& V_{1}(t)=\left|\ln x(t)-\ln x_{1}(t)\right|, \\
& V_{2}(t)=\left|\ln y(t)-\ln y_{1}(t)\right| .
\end{aligned}
$$

Then for $t>T$, we have

$$
\begin{aligned}
& D^{+} V_{1}(t) \\
& \leq \operatorname{sgn}\left(x(t)-x_{1}(t)\right)\left(-b_{1}(t) x(t)-\frac{a_{1}(t)(1-m(t)) y(t)}{(1-m(t)) x(t)+k_{1}(t)}\right. \\
&\left.+b_{1}(t) x_{1}(t)+\frac{a_{1}(t)(1-m(t)) y_{1}(t)}{(1-m(t)) x_{1}(t)+k_{1}(t)}\right) \\
& \leq-b_{1}(t)\left|x(t)-x_{1}(t)\right| \\
&+a_{1}(t)(1-m(t))\left|\frac{y_{1}(t)}{(1-m(t)) x_{1}(t)+k_{1}(t)}-\frac{y(t)}{(1-m(t)) x(t)+k_{1}(t)}\right| \\
&=-b_{1}(t)\left|x(t)-x_{1}(t)\right|+\frac{a_{1}(t)(1-m(t))}{\Delta_{1}\left(x(t), x_{1}(t)\right)} \\
& \times\left|y_{1}(t)\left((1-m(t)) x(t)+k_{1}(t)\right)-y(t)\left((1-m(t)) x_{1}(t)+k_{1}(t)\right)\right| \\
&=-b_{1}(t)\left|x(t)-x_{1}(t)\right|+\frac{a_{1}(t)(1-m(t)) k_{1}(t)}{\Delta_{1}\left(x(t), x_{1}(t)\right)}\left|y(t)-y_{1}(t)\right| \\
&+\frac{a_{1}(t)(1-m(t))^{2}}{\Delta_{1}\left(x(t), x_{1}(t)\right)}\left|y_{1}(t) x(t)-y(t) x_{1}(t)\right| \\
&=-b_{1}(t)\left|x(t)-x_{1}(t)\right|+\frac{a_{1}(t)(1-m(t)) k_{1}(t)}{\Delta_{1}\left(x(t), x_{1}(t)\right)}\left|y(t)-y_{1}(t)\right| \\
&+\frac{a_{1}(t)(1-m(t))^{2}}{\Delta_{1}\left(x(t), x_{1}(t)\right)}\left|y_{1}(t) x(t)-y_{1}(t) x_{1}(t)+y_{1}(t) x_{1}(t)-y(t) x_{1}(t)\right| \\
&=-b_{1}(t)\left|x(t)-x_{1}(t)\right|+\frac{a_{1}(t)(1-m(t)) k_{1}(t)}{\Delta_{1}\left(x(t), x_{1}(t)\right)}\left|y(t)-y_{1}(t)\right| \\
&+\frac{a_{1}(t)(1-m(t))^{2} y_{1}(t)}{\Delta_{1}\left(x(t), x_{1}(t)\right)}\left|x(t)-x_{1}(t)\right| \\
&+\frac{a_{1}(t)(1-m(t))^{2} x_{1}(t)}{\Delta_{1}\left(x(t), x_{1}(t)\right)}\left|y_{1}(t)-y(t)\right| \\
& b_{1}(t)\left|x(t)-x_{1}(t)\right|+\frac{a_{1}(t)(1-m(t)) k_{1}(t)}{\Delta_{1}\left(m_{1}^{\varepsilon}\right)}\left|y(t)-y_{1}(t)\right| \\
&\left.x_{1}\right)
\end{aligned}
$$




$$
\begin{aligned}
& +\frac{a_{1}(t)(1-m(t))^{2}\left(M_{2}+\varepsilon\right)}{\Delta_{1}\left(m_{1}^{\varepsilon}\right)}\left|x(t)-x_{1}(t)\right| \\
& +\frac{a_{1}(t)(1-m(t))^{2}\left(M_{1}+\varepsilon\right)}{\Delta_{1}\left(m_{1}^{\varepsilon}\right)}\left|y_{1}(t)-y(t)\right|
\end{aligned}
$$

and

$$
\begin{aligned}
& D^{+} V_{2}(t) \\
&=\operatorname{sgn}\left(y(t)-y_{1}(t)\right)\left(-\frac{a_{2}(t) y(t)}{(1-m(t)) x(t)+k_{2}(t)}+\frac{a_{2}(t) y_{1}(t)}{(1-m(t)) x_{1}(t)+k_{2}(t)}\right) \\
&=\frac{\operatorname{sgn}\left(y(t)-y_{1}(t)\right)}{\Delta\left(x(t), x_{1}(t)\right)}\left(-a_{2}(t) y(t)\left((1-m(t)) x_{1}(t)+k_{2}(t)\right)\right. \\
&\left.\quad+a_{2}(t) y_{1}(t)\left((1-m(t)) x(t)+k_{2}(t)\right)\right) \\
&=\frac{\operatorname{sgn}\left(y(t)-y_{1}(t)\right)}{\Delta_{2}\left(x(t), x_{1}(t)\right)}\left(-a_{2}(t) k_{2}(t)\left(y(t)-y_{1}(t)\right)\right) \\
& \quad+\frac{\operatorname{sgn}\left(y(t)-y_{1}(t)\right)}{\Delta_{2}\left(x(t), x_{1}(t)\right)}\left(-a_{2}(t)(1-m(t))\left(y(t) x_{1}(t)-y_{1}(t) x(t)\right)\right) \\
& \leq \frac{-a_{2}(t) k_{2}(t)}{\Delta_{2}\left(M_{1}^{\varepsilon}\right)}\left|y(t)-y_{1}(t)\right|+\frac{\operatorname{sgn}\left(y(t)-y_{1}(t)\right)}{\Delta_{2}\left(x(t), x_{1}(t)\right)} \\
& \times\left(-a_{2}(t)(1-m(t))\left(y(t) x_{1}(t)-y_{1}(t) x_{1}(t)+y_{1}(t) x_{1}(t)-y_{1}(t) x(t)\right)\right) \\
& \leq-\frac{a_{2}(t) k_{2}(t)}{\Delta_{2}\left(M_{1}^{\varepsilon}\right)}\left|y(t)-y_{1}(t)\right|-\frac{a_{2}(t)(1-m(t))\left(m_{1}-\varepsilon\right)}{\Delta_{2}\left(M_{1}^{\varepsilon}\right)}\left|y(t)-y_{1}(t)\right| \\
&+\frac{a_{2}(t)(1-m(t))\left(M_{2}+\varepsilon\right)}{\Delta_{2}\left(m_{1}^{\varepsilon}\right)}\left|x(t)-x_{1}(t)\right| .
\end{aligned}
$$

Now let us set

$$
V(t)=V_{1}(t)+V_{2}(t) .
$$

Then

$$
D^{+} V(t) \leq-\Gamma_{1}(\varepsilon, t)\left|x(t)-x_{1}(t)\right|-\Gamma_{2}(\varepsilon, t)\left|y(t)-y_{1}(t)\right| .
$$

Integrating both sides of (3.10) on the interval $[T, t)$,

$$
V(t)-V(T) \leq \int_{T}^{t}\left[-\Gamma_{1}(\varepsilon, s)\left|x(s)-x_{1}(s)\right|-\Gamma_{2}(\varepsilon, s)\left|y(s)-y_{1}(s)\right|\right] d s \quad \text { for } t \geq T .
$$

It follows from (3.4) that

$$
V(t)+\varepsilon \int_{T}^{t}\left[\left|x(s)-x_{1}(s)\right|+\left|y(s)-y_{1}(s)\right|\right] d s \leq V(T) \quad \text { for } t \geq T .
$$

Therefore, $V(t)$ is bounded on $[T,+\infty)$ and also

$$
\int_{T}^{t}\left[\left|x(s)-x_{1}(s)\right|+\left|y(s)-y_{1}(s)\right|\right] d s<+\infty
$$


By Lemma 2.1, 2.2, and Theorem 2.1, $\left|x(t)-x_{1}(t)\right|,\left|y(t)-y_{1}(t)\right|$ are bounded on $[T,+\infty)$. On the other hand, it is easy to see that $\dot{x}(t), \dot{y}(t), \dot{x}_{1}(t)$, and $\dot{y}_{1}(t)$ are bounded for $t \geq T$. Therefore, $\left|x(t)-x_{1}(t)\right|,\left|y(t)-y_{1}(t)\right|$ are uniformly continuous on $[T,+\infty)$. By the Barbălat lemma [47], one can conclude that

$$
\lim _{t \rightarrow+\infty}\left[\left|x(t)-x_{1}(t)\right|+\left|y(t)-y_{1}(t)\right|\right]=0 .
$$

This ends the proof of Theorem 3.1.

\section{Numeric example}

Now let us consider the following example.

\section{Example 4.1}

$$
\begin{aligned}
& \dot{x}(t)=x\left(11+\cos t-6 x-\frac{(1.5+0.5 \sin t)(1-0.1) y}{(1-0.1) x+1}\right), \\
& \dot{y}(t)=y\left(2-\frac{2 y}{(1-0.1) x+2}\right) .
\end{aligned}
$$

Corresponding to system (1.2), one has

$$
\begin{aligned}
& r_{1}(t)=11+\cos t, \quad b_{1}(t)=6, \quad a_{1}(t)=1.5+0.5 \sin t, \quad m(t)=0.1, \\
& k_{1}(t)=1, \quad r_{2}(t)=2, \quad a_{2}(t)=2, \quad k_{2}(t)=2 .
\end{aligned}
$$

And so,

$$
M_{1}=\frac{r_{1}^{M}}{b_{1}^{L}}=2, \quad M_{2}=\frac{r_{2}^{M}\left(\left(1-m^{L}\right) M_{1}+k_{2}^{M}\right)}{a_{2}^{L}}=\frac{2(0.9 \times 2+2)}{2}=3.8
$$

Consequently

$$
r_{1}^{L}-\frac{a_{1}^{M}\left(1-m^{L}\right) M_{2}}{k_{1}^{L}}=10-\frac{2 \times 0.9 \times 3.9}{1}=2.98>0 .
$$

Equation (4.3) shows that (2.8) holds, thus, it follows from Theorem 2.1 that system (4.1) is permanent, and numeric simulations (Figures 1,2) also support these findings.

Figure 1 Dynamic behavior of the first component $x(t)$ of the solution $(x(t), y(t))$ of system (4.1) with the initial condition $(x(0)$, $y(0))=(0.2,5),(0.4,1),(0.6,3)$, and $(4,2)$, respectively.

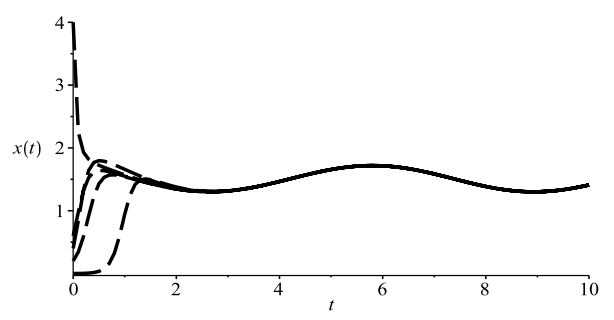


Figure 2 Dynamic behavior of the second component $y(t)$ of the solution $(x(t), y(t))$ of system (4.1) with the initial condition $(x(0)$, $y(0))=(0.2,5),(0.4,1),(0.6,3)$, and $(4,2)$, respectively.

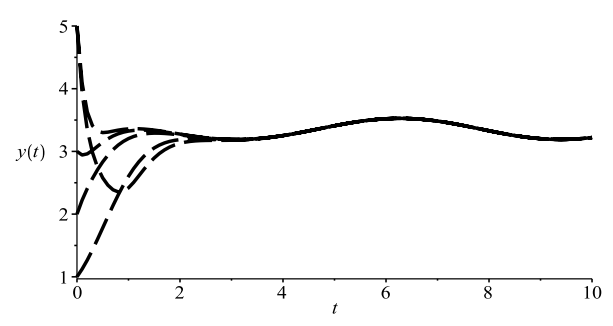

\section{Discussion}

In this paper, we propose and study a nonautonomous modified Leslie-Gower predatorprey model with Holling-type II schemes and a prey refuge. We first obtain a set of sufficient conditions which ensure the permanence of the system, after that, by constructing a suitable Lyapunov function, we also investigate the stability property of the system.

Condition (2.8) implies that the prey refuge has a positive effect on the persistence property of the system, indeed, with the increasing of prey refuge, the predators have difficulty in catching the prey species, this directly increasing the survival possibility of the prey species.

We mention here that in condition $\left(H_{1}\right)$ we make the assumption that the intrinsic growth rate of the prey species is a positive function, however, in some cases, the growth rate may be negative (see [48-50]) and the references therein), we leave this for future investigation.

\section{Competing interests}

The authors declare that there is no conflict of interests.

Authors' contributions

All authors contributed equally to the writing of this paper. All authors read and approved the final manuscript.

\section{Author details}

${ }^{1}$ Department of Mathematics, Ningde Normal University, Ningde, Fujian 352300, P.R. China. ${ }^{2}$ College of Mathematics and Computer Science, Fuzhou University, Fuzhou, Fujian 350002, P.R. China. ${ }^{3}$ College of Mathematics and Computer Science, Fuzhou University, Fuzhou, Fujian 350116, P.R. China.

\section{Acknowledgements}

The authors are grateful to anonymous referees for their excellent suggestions, which greatly improved the presentation of the paper. The research was supported by the Natural Science Foundation of Fujian Province (2015J01012, 2015J01019, 2015J05006) and the Scientific Research Foundation of Fuzhou University (XRC-1438).

Received: 5 May 2016 Accepted: 8 June 2016 Published online: 07 July 2016

\section{References}

1. Yue, Q: Dynamics of a modified Leslie-Gower predator-prey model with Holling-type II schemes and a prey refuge. SpringerPlus 5, Article ID 461 (2016)

2. $\mathrm{Wu}, \mathrm{Y}, \mathrm{Chen}, \mathrm{F}, \mathrm{Chen}, \mathrm{W}, \mathrm{Lin}, \mathrm{Y}$ : Dynamic behaviors of a nonautonomous discrete predator-prey system incorporating a prey refuge and Holling type II functional response. Discrete Dyn. Nat. Soc. 2012, Article ID 508962 (2012)

3. Chen, $F, W u, Y, M a, Z$ : Stability property for the predator-free equilibrium point of predator-prey systems with a class of functional response and prey refuges. Discrete Dyn. Nat. Soc. 2012, Article ID 148942 (2012)

4. Chen, W, Gong, X, Zhao, L, Zhang, H: Dynamics of a non-autonomous discrete Leslie-Gower predator-prey system with prey refuge. J. Fuzhou Univ. 43(1), 6-10 (2015)

5. $\mathrm{Wu}, \mathrm{Y}, \mathrm{Chen}, \mathrm{WL}$, Zhang, $\mathrm{HY}$ : On permanence and global attractivity of a nonautonomous modified Leslie-Gower predator-prey system incorporating a prey refuge. J. Minjiang Univ. 33(5), 13-16 (2012)

6. $\mathrm{Ma}, \mathrm{ZZ}$, Chen, FD, Wu, CQ, Chen, WL: Dynamic behaviors of a Lotka-Volterra predator-prey model incorporating a prey refuge and predator mutual interference. Appl. Math. Comput. 219(15), 7945-7953 (2013)

7. Chen, FD, Ma, ZZ, Zhang, HY: Global asymptotical stability of the positive equilibrium of the Lotka-Volterra prey-predator model incorporating a constant number of prey refuges. Nonlinear Anal., Real World Appl. 13(6), 2790-2793 (2012)

8. Yang, $R$, Zhang, C: The effect of prey refuge and time delay on a diffusive predator-prey system with hyperbolic mortality. Complexity 50(3), 105-113 (2016) 
9. Yang, R, Zhang, C: Dynamics in a diffusive predator-prey system with a constant prey refuge and delay. Nonlinear Anal., Real World Appl. 31, 1-22 (2016)

10. $\mathrm{Wu}, \mathrm{Y}, \mathrm{Chen}, \mathrm{F}, \mathrm{Ma}, \mathrm{Z}$ : Extinction of predator species in a non-autonomous predator-prey system incorporating prey refuge. Appl. Math.-J. Chinese Univ. Ser. A 27(3), 359-365 (2012)

11. $W u, Y, C h e n, F, M a, Z, L i n, Y:$ Permanence and extinction of a non-autonomous predator-prey system incorporating prey refuge and Rosenzweig functional response. J. Biomath. 29(4), 727-731 (2014)

12. Kar, TK: Modelling and analysis of a harvested prey-predator system incorporating a prey refuge. J. Comput. Appl. Math. 185, 19-33 (2006)

13. Wang, Y, Wang, JZ: Influence of prey refuge on predator-prey dynamics. Nonlinear Dyn. 67, 191-201 (2012)

14. Sih, A: Prey refuges and predator-prey stability. Theor. Popul. Biol. 31(1), 1-12 (1987)

15. González-Olivares, E, Ramos-Jiliberto, R: Dynamic consequences of prey refuges in a simple model system: more prey, fewer predators and enhanced stability. Ecol. Model. 166, 135-146 (2003)

16. Kar, TK: Stability analysis of a prey-predator model incorporating a prey refuge. Commun. Nonlinear Sci. Numer. Simul. 10, 681-691 (2005)

17. Chen, FD, Chen, LJ, Xie, XD: On a Leslie-Gower predator-prey model incorporating a prey refuge. Nonlinear Anal., Real World Appl. 10(5), 2905-2908 (2009)

18. Sih, A, Petranka, JW, Kats, LB: The dynamics of prey refuge use: a model and tests with sunfish and salamander larvae. Am. Nat. 132(4), 464-483 (1988)

19. McNair, JN: The effects of refuges on predator-prey interactions: a reconsideration. Theor. Popul. Biol. 29(1), 38-63 (1986)

20. McNair, JN: Stability effects of prey refuge with entry-exit dynamics. J. Theor. Biol. 125, 449-464 (1987)

21. Chen, LJ, Chen, FD, Chen, LJ: Qualitative analysis of a predator-prey model with Holling type II functional response incorporating a constant prey refuge. Nonlinear Anal., Real World Appl. 11(1), 246-252 (2010)

22. Chen, LJ, Chen, FD: Global analysis of a harvested predator-prey model incorporating a constant prey refuge. Int. J. Biomath. 3(2), 205-223 (2010)

23. Ji, LL, Wu, CQ: Qualitative analysis of a predator-prey model with constant-rate prey harvesting incorporating a constant prey refuge. Nonlinear Anal., Real World Appl. 11(4), 2285-2295 (2010)

24. Kar, TK, Misra, S: Influence of prey reserve in a prey-predator fishery. Nonlinear Anal. 65(9), 1725-1735 (2006)

25. Tao, YD, Wang, X, Song, XY: Effect of prey refuge on a harvested predator-prey model with generalized functional response. Commun. Nonlinear Sci. Numer. Simul. 16(2), 1052-1059 (2011)

26. Huang, YJ, Chen, FD, Li, Z: Stability analysis of a prey-predator model with Holling type III response function incorporating a prey refuge. Appl. Math. Comput. 182, 672-683 (2006)

27. Ko, W, Ryu, K: Qualitative analysis of a predator-prey model with Holling type II functional response incorporating a prey refuge. J. Differ. Equ. 231, 534-550 (2006)

28. Shuai, ZS, Miao, CM, Zhang, WP, et al.: Model of a three interacting prey-predator with refuges. J. Biomath. 19(1), 65-71 (2004) (in Chinese)

29. Zhu, J, Liu, HM: Permanence of the two interacting prey-predator with refuges. J. Northwest Univ. National. (Nat. Sci.) 27(62), 1-3 (2006) (in Chinese)

30. $\mathrm{Xu}, \mathrm{GM}, \mathrm{Chen}, \mathrm{XH}$ : Persistence and periodic solution for three interacting predator-prey system with refuges. Yinshan Academic J. 23(1), 14-17 (2009) (in Chinese)

31. Xu, GM, Jia, JW: Stability analysis of a predator-prey system with refuges. J. Shanxi Normal Univ. (Nat. Sci. Ed.) 21(4), 4-7 (2007) (in Chinese)

32. $\mathrm{Yu}, \mathrm{SP}$, Xiong, $\mathrm{WT}, \mathrm{Qi}, \mathrm{H}$ : A ratio-dependent one predator-two competing prey model with delys and refuges. Math. Appl. 23(1), 198-203 (2010)

33. Zhang, YB, Wang, WX, Duan, YH: Analysis of prey-predator with Holling III functional response and prey refuge. Math. Pract. Theory 40(24), 149-154 (2010) (in Chinese)

34. Zhuang, KJ, Wen, ZH: Dynamical behaviors in a discrete predator-prey model with a prey refuge. Int. J. Comput. Math. Sci. 5(4), 194-197 (2011)

35. Krivan, V: On the Gause predator-prey model with a refuge: a fresh look at the history. J. Theor. Biol. 274(1), 67-73 (2011)

36. $\mathrm{Ma}, \mathrm{ZH}, \mathrm{Li}, \mathrm{WL}$, Zhao, Y, et al.: Effects of prey refuges on a predator-prey model with a class of functional response: the role of refuges. Math. Biosci. 218, 73-79 (2009)

37. $\mathrm{Ma}, \mathrm{ZH}, \mathrm{Li}, \mathrm{WD}$, Wang, SF: The effect of prey refuge in a simple predator-prey model. Ecol. Model. 222(18), 3453-3454 (2011)

38. Cressman, R, Garay, J: A predator-prey refuge system: evolutionary stability in ecological systems. Theor. Popul. Biol. 76(4), 248-257 (2009)

39. Yu, S: Global stability of a modified Leslie-Gower model with Beddington-DeAngelis functional response. Adv. Differ Equ. 2014, Article ID 84 (2014)

40. Yu, S: Global asymptotic stability of a predator-prey model with modified Leslie-Gower and Holling-type II schemes. Discrete Dyn. Nat. Soc. 2012, Article ID 208167 (2012)

41. Chen, J, Yu, S: Permanence for a discrete ratio-dependent predator-prey system with Holling type III functional response and feedback controls. Discrete Dyn. Nat. Soc. 2013, Article ID 326848 (2013)

42. Li, Z, Han, M, Chen, F: Global stability of a stage-structured predator-prey model with modified Leslie-Gower and Holling-type II schemes. Int. J. Biomath. 5, Article ID 1250057 (2012)

43. Zhang, N, Chen, F, Su, Q, et al.: Dynamic behaviors of a harvesting Leslie-Gower predator-prey model. Discrete Dyn. Nat. Soc. 2011, Article ID 473949 (2011)

44. Chen, LJ, Chen, FD: Global stability of a Leslie-Gower predator-prey model with feedback controls. Appl. Math. Lett. 22(9), 1330-1334 (2009)

45. Wu, R, Lin, L: Permanence and global attractivity of the discrete predator-prey system with Hassell-Varley-Holling III type functional response. Discrete Dyn. Nat. Soc. 2009, Article ID 393729 (2009)

46. Chen, FD, Li, Z, Huang, YJ: Note on the permanence of a competitive system with infinite delay and feedback controls. Nonlinear Anal., Real World Appl. 8, 680-687 (2007) 
47. Barbălat, I: Systèmes d'équations differential d'oscillations nonlinéaires. Rev. Roum. Math. Pures Appl. 4(2), 267-270 (1959)

48. Chen, FD, You, MS: Permanence, extinction and periodic solution of the predator-prey system with Beddington-DeAngelis functional response and stage structure for prey. Nonlinear Anal., Real World Appl. 9(2), 207-221 (2008)

49. Chen, FD, Shi, JL: On a delayed nonautonomous ratio-dependent predator-prey model with Holling type functional response and diffusion. Appl. Math. Comput. 192(2), 358-369 (2007)

50. Chen, FD, Huang, AM: On a nonautonomous predator-prey model with prey dispersal. Appl. Math. Comput. 184(2), 809-822 (2007)

Submit your manuscript to a SpringerOpen ${ }^{\circ}$ journal and benefit from:

- Convenient online submission

Rigorous peer review

- Immediate publication on acceptance

- Open access: articles freely available online

- High visibility within the field

- Retaining the copyright to your article 